\title{
Oral acyclovir (Zovirax) in herpes simplex dendritic corneal ulceration
}

\author{
L M T COLlum,' P McGeTtRick,' J AKHTAR,' J LAVIN,' ANd P J REES \\ From the 'Royal Victoria Eye and Ear Hospital, Dublin, and the ${ }^{2}$ Wellcome Research Laboratories, \\ Beckenham, Kent
}

SUMMARY Sixty patients with simple dendritic corneal ulceration were randomly assigned to double blind treatment with either acyclovir tablets $(400 \mathrm{mg})$ or acyclovir ophthalmic ointment administered five times daily. There was no significant difference in the proportions of patients healed in either treatment group $(88.9 \%$ on oral acyclovir and $96.6 \%$ on acyclovir ointment). The median healing time was five days in both groups. No systemic or significant local side effects were noted in either treatment group. Trough levels of acyclovir in the tear fluid of those who received the oral preparation were within or above the range of mean in-vitro ID $_{50}$ levels for herpes simplex virus type 1 . We conclude that oral administration of acyclovir ( $400 \mathrm{mg}$, five times daily) may be an effective alternative to topical therapy in selected patients.

Acyclovir is a highly effective antiherpes agent and has a selective action against herpes virus infected cells. ${ }^{2}$ Jones et al. in $1979^{3}$ showed that acyclovir was effective clinically in the control of herpes simplex eye infections, and since then it has been shown to be at least as effective as, ${ }^{\text {th }}$ or more effective than, ${ }^{7-11}$ idoxuridine and adenine arabinoside, and broadly equivalent to trifluorothymidine ${ }^{12}$ in the management of dendritic corneal ulceration. There have been no significant side effects associated with its use, and it has been shown to be an acceptable alternative to any of the other antiviral agents. ${ }^{13}$

There is no doubt that the local antivirals available are effective in the management of herpes simplex dendritic corneal ulceration. Nevertheless there are patients who find it extremely difficult to use local treatment, either because they are unwilling to instill medication into their eye, or because they are either psychologically or physically unable to do so. Patients who have Parkinson's disease or rheumatoid arthritis, those who are elderly and unable to perform simple chores, and those whose occupation may prevent them from instilling ointment into their eye during the working day would therefore benefit from a safe, effective oral medication which would be more acceptable and easier for them to take. In addition the use of a systemic antiviral may produce

Correspondence to Professor L M T Collum, 54 Adelaide Road, Dublin 2. an effect deeper in the eye and might be useful in more complicated forms of herpes simplex ocular disease, such as stromal keratitis or uveitis. Systemic acyclovir has been extensively used in the management of herpes simplex mucocutaneous disease, ${ }^{14}$ with remarkably few side effects. It has been shown that in patients receiving oral doses of $400 \mathrm{mg}$ acyclovir five times daily the levels of drug in the aqueous humour were in excess of the normal in vitro $\mathrm{ID}_{50}$ range for herpes simplex virus type $1 .^{15}$

A pilot study carried out at the Royal Victoria Eye and Ear Hospital, Dublin, in which eight patients were treated with oral acyclovir for simple dendritic ulceration resulted in the condition healing in all of them. Because of this apparently favourable response a double blind controlled study was set up to compare the efficacy of oral and local acyclovir in the management of simple dendritic corneal ulceration. This paper reports the results of this study.

\section{Material and methods}

Sixty patients with simple dendritic corneal ulceration were included in this study, having given their informed consent. Excluded were those who had been treated with antivirals within the previous six months, those who had used topical steroids at any time, and those who had any other associated ocular disease. Also excluded were uniocular patients, children under 14 years, and women of child bearing 
age. Each patient was seen at least three times weekly or more frequently if necessary. If there were any doubts about a patient's ability to comply with the dosing regimen or if the ulcer was particularly large the patient was admitted to hospital at the beginning of treatment. Mydriatics and eye padding were used as appropriate. The diagnosis was based on the history and clinical appearance of the lesion, and at each visit a full ocular examination was carried out and the results recorded.

On a random basis patients were allocated either $3 \%$ acyclovir ophthalmic ointment and placebo tablets, or placebo ointment and acyclovir tablets $(400 \mathrm{mg})$. All medication was to be taken five times daily. If the condition showed no improvement within four days, deteriorated at any time during the study, or failed to heal by 14 days the patient was withdrawn and alternative treatment was given. Healing was deemed to have taken place when there was no further staining with fluorescein, though slight irregularity or cystic change in the epithelium might still exist. All possible adverse reactions were recorded. Blood and tear fluid samples were collected from all patients approximately 48 hours after starting treatment, for measurement of acyclovir concentrations. The specimens were collected four hours after the previous dose for standardisation of all measurements at approximately the trough levels, and acyclovir concentrations were measured by radioimmunoassay conducted by the Department of Clinical Pharmacology, Wellcome Research Laboratories.

Treatment groups were compared on entry for sex, whether they had experienced a previous attack, whether there was any uveal involvement, and for ulcer size by a $\chi^{2}$ test. A $t$-test was used to compare the ages of the two groups. The duration and severity of their symptoms and the extent of stromal infiltration were compared between groups by the nonparametric Mann-Whitney U test. The time to healing after starting treatment was compared between the two groups by a log rank analysis.

\section{Results}

Of the 60 patients who entered the study three receiving the oral medication failed to come for follow-up, and one was lost from the local therapy group. Statistical analyses showed that there were no significant differences between the treatment groups at entry in any variable (Table 1) except that the group receiving oral acyclovir had a significantly longer duration of symptoms $(p<0 \cdot 05)$. The duration of symptoms prior to therapy was included as a covariate in a regression analysis for time to healing after starting treatment. There was no relationship
Table 1 Summary of patient characteristics at presentation

\begin{tabular}{lcc}
\hline & $\begin{array}{c}\text { Oral } \\
\text { acyclovir }\end{array}$ & $\begin{array}{l}\text { Acyclovir } \\
\text { ophthalmic } \\
\text { ointment }\end{array}$ \\
\hline Sex: male $\quad 21$ & 24 \\
female & 6 & 5 \\
Age (years), mean & $44 \cdot 7$ & $50 \cdot 0$ \\
Previous attack, percentage & $29 \cdot 6$ & $51 \cdot 7$ \\
Duration of symptoms (days), mean & $7 \cdot 6$ & $4 \cdot 6^{*}$ \\
Severity of symptoms (score), mean & $2 \cdot 3$ & $2 \cdot 3$ \\
Stromal infiltration (score), mean & $0 \cdot 7$ & $0 \cdot 8$ \\
Uveitis, percentage & $25 \cdot 9$ & $34 \cdot 5$ \\
Ulcer size: small & 8 & 9 \\
$\quad$ large & 11 & 9 \\
$\quad$ multiple & 8 & 11 \\
\hline
\end{tabular}

${ }^{*} \mathrm{p}<0 \cdot 05$.

between symptom duration and healing time, and the difference between the two groups at entry was considered unlikely to bias the results.

There was no significant difference between the treatment groups in the number of patients healed by 14 days. Healing was achieved in $24(88.9 \%)$ of the 27 oral acyclovir recipients and in $28(96 \cdot 6 \%)$ of the 29 patients treated with acyclovir ophthalmic ointment. The median time to healing (five days) was identical for both groups (Fig. 1).

Trough levels of acyclovir approximately four hours after the previous dose were determined. For patients receiving oral acyclovir samples of tear fluid and plasma were obtained an average of four hours after the dose on the second day of therapy and after an average of 9.6 previous doses. Samples of tear fluid from 24 patients and plasma from 26 patients were included in the calculation of mean values (Table 2). The mean trough concentrations of acyclovir were $0.6 \mu \mathrm{M}$ (range 0.09 to $1.55 \mu \mathrm{M}$ ) in the tear fluid and $3.28 \mu \mathrm{M}$ (range 0.96 to $8.79 \mu \mathrm{M}$ ) in the plasma.

For patients receiving acyclovir ophthalmic oint-

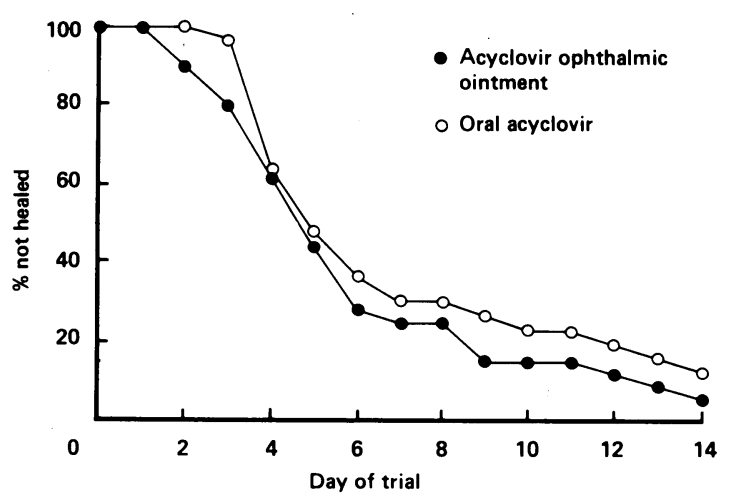

Fig. 1 Cumulative frequency distribution of time taken to heal. 
ment samples ${ }^{\circ}$ were obtained four hours after an average of 9.4 previous doses. Samples of tear fluid from 26 patients and plasma from 27 patients were assayed (Table 2). The acyclovir concentration in tear fluid showed extreme variability, ranging from 0.34 to $2068.44 \mu \mathrm{M}$, believed to be due to contamination of many of the samples with the acyclovir ointment itself. Plasma acyclovir levels were all at or below the limit of detection of the assay $(0.01 \mu \mathrm{M})$.

No serious side effects were recorded, and no patient was withdrawn from the study because of adverse effects. In four patients receiving acyclovir ointment large punctate epithelial defects were noted, but in two of these there was coexisting tear film disease. One other patient receiving acyclovir ointment had a minor degree of superficial punctate epitheliopathy. This disappeared quickly and was not considered significant. Some stinging was reported by three patients, two receiving acyclovir tablets and one receiving acyclovir ointment.

Four patients (three who had received oral acyclovir and one who had received acyclovir oint-

Table 2 Acyclovir concentrations in tear fluid and plasma following oral or topical administration

\begin{tabular}{|c|c|c|c|c|c|}
\hline \multicolumn{3}{|c|}{ Oral acyclovir } & \multicolumn{3}{|c|}{ Acyclovir ophthalmic ointment } \\
\hline \multirow[b]{2}{*}{$\begin{array}{l}\text { Patient } \\
\text { number }\end{array}$} & \multicolumn{2}{|c|}{$\begin{array}{l}\text { Acyclovir } \\
\text { concentration }(\mu M)\end{array}$} & \multirow[b]{2}{*}{$\begin{array}{l}\text { Patient } \\
\text { number }\end{array}$} & \multicolumn{2}{|c|}{$\begin{array}{l}\text { Acyclovir } \\
\text { concentration }(\mu M)\end{array}$} \\
\hline & $\begin{array}{l}\text { Tear } \\
\text { fluid }\end{array}$ & Plasma & & $\begin{array}{l}\text { Tear } \\
\text { fluid }\end{array}$ & Plasma \\
\hline 1 & $<0.01^{*}$ & 0.96 & 3 & $>5 \cdot 0$ & $<0.01$ \\
\hline 2 & $<0.01^{*}$ & $6 \cdot 62$ & 4 & $>11.0$ & $<0.01$ \\
\hline 6 & $0 \cdot 16$ & $1 \cdot 83$ & 5 & $>9.0$ & $<0.01$ \\
\hline 8 & $0 \cdot 28$ & $1 \cdot 39$ & 7 & $>3.0$ & $<0.01$ \\
\hline 9 & 0.36 & 6.08 & 10 & 3.73 & $<0.01$ \\
\hline 12 & 1.01 & $2 \cdot 06$ & 11 & $42 \cdot 7$ & $<0.01$ \\
\hline 14 & 0.43 & $2 \cdot 23$ & 13 & - & $<0.01$ \\
\hline 16 & $1 \cdot 28$ & $4 \cdot 28$ & 17 & $34 \cdot 3$ & $<0.01$ \\
\hline 19 & 0.92 & $3 \cdot 32$ & 18 & $9 \cdot 71$ & $<0.01$ \\
\hline 22 & $0 \cdot 22$ & 3.03 & 20 & $>130 \cdot 0$ & $<0.01$ \\
\hline 23 & 1.08 & $6 \cdot 62$ & 21 & 1.87 & $<0.01$ \\
\hline 25 & $0 \cdot 27$ & $3 \cdot 16$ & 24 & $108 \cdot 32$ & $<0.01$ \\
\hline 27 & 0.25 & $1 \cdot 78$ & 26 & $42 \cdot 84$ & $<0.01$ \\
\hline 29 & 1.45 & 6.87 & 28 & $78 \cdot 43$ & $<0.01$ \\
\hline 31 & $1 \cdot 17$ & 8.79 & 30 & 0.34 & $<0.01$ \\
\hline 32 & 0.09 & $1 \cdot 71$ & 33 & $131 \cdot 74$ & $<0.01$ \\
\hline 35 & 0.26 & 1.49 & 34 & $15 \cdot 05$ & 0.01 \\
\hline 36 & $0 \cdot 12$ & 1.45 & 39 & $524 \cdot 91$ & $<0.01$ \\
\hline 41 & 0.74 & 1.69 & 44 & $75 \cdot 13$ & $<0.01$ \\
\hline 42 & $0 \cdot 20$ & $2 \cdot 47$ & 48 & $46 \cdot 27$ & 0.01 \\
\hline 45 & 0.69 & $4 \cdot 49$ & 49 & 0.80 & $<0.01$ \\
\hline 46 & 0.76 & $2 \cdot 85$ & 50 & $50 \cdot 32$ & 0.01 \\
\hline 47 & $5 \cdot 26^{*}$ & $2 \cdot 03$ & 51 & $428 \cdot 34$ & $<0.01$ \\
\hline 52 & $1 \cdot 55$ & - & 55 & 0.87 & $<0.01$ \\
\hline 54 & $0 \cdot 17$ & $1 \cdot 50$ & 57 & $2068 \cdot 44$ & 0.01 \\
\hline 56 & 0.71 & $3 \cdot 81$ & 58 & $91 \cdot 19$ & 0.01 \\
\hline 60 & $0 \cdot 24$ & $2 \cdot 75$ & 59 & $19 \cdot 15$ & $<0.01$ \\
\hline
\end{tabular}

*Values excluded from calculation of mean: low sample volumes prevented accurate assay. ment) subsequently developed disciform keratitis. One patient treated with acyclovir ointment had a recurrence of his dendritic ulcer three weeks after the initial lesion had healed.

\section{Discussion}

Locally applied acyclovir ophthalmic ointment is now accepted as a standard treatment for corneal epithelial herpetic keratitis. There is a group of patients, as mentioned above, who would benefit from an effective oral medication. This study has shown that oral acyclovir is as effective as locally applied acyclovir in the management of herpes simplex dendritic corneal ulceration.

The mean trough plasma level of acyclovir in the study patients who received oral drug $(3.28 \mu \mathrm{M})$ is similar to values reported previously. ${ }^{1617}$ These levels are considerably lower than the concentrations of drug routinely achieved by intravenous administration $^{18}$ and are therefore well within tolerance limits. The mean in-vitro $\mathrm{ID}_{50}$ values for herpes simplex virus type 1 range from 0.08 to $0.5 \mu \mathrm{M}$ acyclovir. ${ }^{19}$ The mean trough acyclovir concentration in the tear fluid of patients taking the oral drug $(0 \cdot 6 \mu \mathrm{M})$ was above the upper end of this range, and all individual values fell within or above the sensitivity range of the virus.

As there were no significant systemic or local side effects, oral medication would therefore appear to provide an acceptable alternative for patients who are unable or unwilling to use local treatment for their disease. This study has shown that $400 \mathrm{mg}$ of acyclovir given five times daily by mouth would be an effective alternative therapy in selected patients in the management of dendritic corneal ulceration.

The authors wish to express their gratitude to $\mathrm{Mr} \mathrm{S}$ Jeal, Mrs J Fox, and their colleagues in the Clinical Pharmacology Department and to Ms K Booth of the Clinical Statistics Section at Wellcome Research Laboratories for their excellent assistance.

\section{References}

1 Elion GB, Furman PA, Fyfe JA, de Miranda P, Beauchamp L, Schaeffer HJ. Selectivity of action of an antiherpetic agent, 9-(2hydroxyethoxymethyl) guanine. Proc Natl Acad Sci USA 1977; 74: 5716-20.

2 Schaeffer Beauchamp L, de Miranda P, Elion GB, Bauer DJ, Collins P. 9-(2-hydroxyethoxymethyl) guanine activity against viruses of the herpes group. Nature $1978 ; 272$ : 583-5.

3 Jones BR, Coster DJ, Fison PN, Thompson GM, Cobo LM, Falcon MG. Efficacy of acycloguanosine (Wellcome 248U) against herpes simplex corneal ulcers. Lancet 1979 ; i: 243-4.

4 Coster DJ, Wilhelmus KR, Michaud R, Jones BR. A comparison of acyclovir and idoxuridine as treatment for ulcerative herpetic keratitis. Br J Ophthalmol 1980; 64: 763-5.

5 McCulley JP, Binder PS, Kaufman HE, O'Day DM, Poirier RH. A double-blind multicenter clinical trial of acyclovir vs. idoxuridine for treatment of epithelial herpes simplex keratitis. Ophthalmology (Rochester) 1982; 89: 1195-200. 
6 Laibson PR, Pavan-Langston D, Yeakley WR, Lass J. Acyclovir and vidarabine for the treatment of herpes simplex keratitis. $A m$ J Med 1982; 73: 281-5.

7 Collum LMT, Benedict-Smith A, Hillary IB. Randomised double-blind trial of acyclovir and idoxuridine in dendritic corneal ulceration. BrJ Ophthalmol 1980; 64: 766-9.

8 Colin J, Tournoux A, Chastel C, Renard G. Superficial herpes simplex keratitis. Double-blind comparative trial of acyclovir and idoxuridine. Nouv Presse Med 1981; 10: 2969-75.

9 Klauber A, Ottovay E. Acyclovir and idoxuridine treatment of herpes simplex keratitis-a double blind clinical study. Acta Ophthalmol (Kbh) 1982; 60: 838-44.

10 McGill J, Tormey P, Walker CB. Comparative trial of acyclovir and adenine arabinoside in the treatment of herpes simplex corneal ulcers. Br J Ophthalmol 1981; 65: 610-3.

11 Young BJ, Patterson A, Ravenscroft T. A randomised doubleblind clinical trial of acyclovir (Zovirax) and adenine arabinoside in herpes simplex corneal ulceration. Br J Ophthalmol 1982; 66: 361-3.

12 La Lau C, Oosterhuis JA, Versteeg J, et al. Acyclovir and trifluorothymidine in herpetic keratitis-a multicentre trial. $\mathrm{BrJ}$ Ophthalmol 1982; 66: 506-8.

13 Collum LMT, Benedict-Smith A. Acyclovir (Zovirax) in herpes simplex keratitis. In: $\mathbf{R}$ Sundmacher, ed. Herpetische Augenerkrankungen. Munich: Bergmann, 1981:323-7.
14 Field HJ, Phillips I, eds. Proceedings of the second international acyclovir symposium, London, 15-18 May 1983. J Antimicrob Chemother 1983; 12B.

15 Hung SO, Patterson A, Rees PJ. Pharmacokinetics of oral acyclovir (Zovirax) in the cyc. Br J Ophthalmol 1984; 68: 192-5.

16 de Miranda P, Whitely RJ, Barton N, et al. Systemic absorption and pharmacokinetics of acyclovir (ACV) (Zovirax) capsules in immunocompromised patients with herpesvirus infections. In: Program and Abstracts of the 22nd Interscience Conference on Antimicrobial Agents and Chemotherapy. American Society for Microbiology: Washington, DC, 1982: 140.

17 Van Dyke R, Straube R, Large K, Hintz M, Spector S, Connor JD. Pharmacokinetics of increased dose oral acyclovir. In: Program and Abstracts of the 22nd Interscience Conference on Antimicrobial Agents and Chemotherapy. American Society for Microbiology: Washington, DC, 1982: 139.

18 Whitley RJ, Blum MR, Barton N, de Miranda P. (1982). The pharmacokinetics of acyclovir in humans following intravenous administration: a model for the development of parenteral antivirals. Am J Med 1982; 73: 165-71.

19 Collins $P$. The spectrum of antiviral activities of acyclovir in vitro and in vivo. J Antimicrob Chemother 1983; 12B: 19-27.

Accepted for publication 17 October 1985. 